\title{
Comprehensive analysis of soil nitrogen removal by catch crops based on growth and water use
}

\author{
D. Yasutake ${ }^{1 *}$, K. Kondo ${ }^{2}$, S. Yamane ${ }^{3}$, M. Kitano ${ }^{1}$, M. Mori ${ }^{3}$, and T. Fujiwara ${ }^{3}$ \\ ${ }^{1}$ Faculty of Agriculture, Kyushu University, 6-10-1 Hakozaki, Higashi-ku, Fukuoka, 812-8581, Japan \\ ${ }^{2}$ The United Graduate School of Agricultural Sciences, Ehime University, Ehime, 790-8566, Japan \\ ${ }^{3}$ Agriculture Unit, Natural Sciences Cluster, Research and Education Faculty, Kochi University, Kochi, 783-8502, Japan
}

Received March 2, 2015; accepted May 30, 2016

\begin{abstract}
A b s t r a c t. A new methodology for comprehensive analysis of the characteristics of nitrogen $(\mathrm{N})$ removal from greenhouse soil by catch crop was proposed in relation to its growth and water use. The $\mathrm{N}$ removal is expressed as the product of five parameters: net assimilation rate, specific leaf area, shoot dry weight, water use efficiency for $\mathrm{N}$ removal, and water requirement for growth. This methodology was applied to the data of a greenhouse experiment where corn was cultivated under three plant densities. We analyzed the effect of plant density and examined the effectiveness of the methodology. Higher plant densities are advantageous not only for total $\mathrm{N}$ removal but also for water use efficiency in $\mathrm{N}$ removal and growth because of the large specific leaf area, shoot dry weight, and decreased soil evaporation. On the other hand, significant positive or negative linear relationships were found between all five parameters and $\mathrm{N}$ removal. This should improve the understanding of the $\mathrm{N}$ removal mechanisms and the interactions among its components. We show the effectiveness of our analytical methodology, which can contribute to identifying the optimum plant density according to the field situations (available water amount, soil $\mathrm{N}$ quantity to be removed) for practical catch crop cultivation.
\end{abstract}

K e y w o r d s: corn, evapotranspiration, greenhouse, growth analysis, plant density

\section{INTRODUCTION}

The use of greenhouses in agriculture has increased worldwide, and a large proportion of these are under soilbased cultivation (Bonachela et al., 2012). In such greenhouses, nutrient salts gradually accumulate in the soil because of fertilizer overuse and the absence of leaching with rainfall (Shi et al., 2009). This has been shown to

*Corresponding author e-mail: yasutake@bpes.kyushu-u.ac.jp

**This work was financially supported by the Core Research for Evolutionary Science and Technology (CREST) of the Japan Science and Technology Agency (JST), and a Grant-in-Aid for Scientific Research (No. 15K07668) from the Japan Society for the Promotion of Science (2009-2015). negatively influence crop growth through an excess of nutrients and/or an osmotic effect (Fujimaki and Kikuchi, 2010; Redwan et al., 2016). In Japan, to overcome this problem in greenhouse horticulture, the field is typically flooded during a fallow period (generally in the summer) after cultivation of commercial crops to leach the accumulated salts downwards. This flooding practice seems to be an effective method for salt removal in greenhouses; however, it causes serious environmental problems such as nitrate groundwater pollution and the emission of nitrous oxide $\left(\mathrm{N}_{2} \mathrm{O}\right)$ gas due to residual nitrogen $(\mathrm{N})$ in the soil (Fujiwara et al., 2002; Sadamatsu et al., 2008). Therefore, environmentally friendly methods of salt and $\mathrm{N}$ removal from the soil are required for sustainable management of greenhouse cropping systems.

One method that has attracted much attention is catch crop cultivation, which is a general term for non-commercial crops that are grown for the purpose of improving soil properties by removing residual $\mathrm{N}$ from the soil via root uptake (Min et al., 2011; Rinnofner et al., 2008). Fujiwara (2012) introduced an innovative and sustainable $\mathrm{N}$ removal system with using corn as a catch crop in greenhouse management and conducted various experiments for the evaluation, improvement, and practical use of the technique. Kondo et al. (2013) investigated the seasonal effects of catch crop cultivation at different plant densities and the results showed high performance with an $82-91 \%$ reduction in nitrate leaching in any season (spring, summer, or winter) and an $89 \%$ reduction in $\mathrm{N}_{2} \mathrm{O}$ gas emission in summer under dense planting (110 plants $\left.\mathrm{m}^{-2}\right)$. Furthermore, the implementation time required for this catch crop

(C) 2016 Institute of Agrophysics, Polish Academy of Sciences 
system was also shortened while retaining its performance (Yasutake et al., 2014a), making it easier to apply to commercially cultivated fields.

Thus, catch crop performance has been demonstrated as sufficient for practical use, but optimal catch crop cultivation has not yet been identified from the viewpoint of plant density. Plant density affects crop growth and water use (Nyakudya and Stroosnijder, 2014), which are both closely related to root uptake (ie $\mathrm{N}$ removal). In particular, water use and its related parameters are extremely important factors in worldwide agricultural systems (Kramer and Boyer, 1995). Therefore, it is important to select the adequate plant density by considering not only the total $\mathrm{N}$ removal but also the water use efficiencies for growth and $\mathrm{N}$ removal, and other agrophysical and physiological parameters. We have previously analyzed how the dynamics of growth, evapotranspiration and its components (transpiration and evaporation), and nutrient salt ( $\mathrm{N}$ and others) uptake in catch crop fields are affected by plant density (Yasutake et al., 2011, 2014b). However, the interactions among these processes were not fully understood in either in our previous studies (Kondo et al., 2013; Yasutake et al., 2011, 2014a, 2014b) or other related studies using catch crops (Min et al., 2011; Rinnofner et al., 2008).

In the current study, we propose a new methodology for the comprehensive analysis of the $\mathrm{N}$ removal characteristics associated with the growth and water use of a catch crop canopy. This analytical methodology was applied to the data obtained from a greenhouse cultivation experiment (Yasutake et al., 2014b) in which corn was used as the catch crop and was cultivated at three different plant densities. The goals of this study were as follows:

- to analyze the comprehensive mechanisms underlying the effect of plant density on $\mathrm{N}$ removal in relation to crop growth and water use and

- to examine the effectiveness of our newly proposed analytical methodology in the agrophysical context.

\section{MATERIALS AND METHODS}

The $\mathrm{N}$ uptake rate $\left(Q_{\mathrm{N}}, \mathrm{gN} \mathrm{m}^{-2} \mathrm{~d}^{-1}\right)$, corresponding to the $\mathrm{N}$ removal by a catch crop, accompanies an increase in crop dry matter (ie growth). Therefore, $Q_{\mathrm{N}}$ can be expressed by the equation below using two important parameters: the growth rate $\left(G R, \mathrm{gDW} \mathrm{m} \mathrm{m}^{-2} \mathrm{~d}^{-1}\right)$ and the $\mathrm{N}$ uptake rate per unit growth rate $\left(Q_{\mathrm{N}} / G R, \mathrm{gN} \mathrm{g}^{-1} \mathrm{DW}\right)$ of the crop canopy.

$$
Q_{\mathrm{N}}=G R Q_{\mathrm{N}} / G R,
$$

where: $Q_{\mathrm{N}} / G R$ also indicates the $\mathrm{N}$ concentration of dry matter of the crop body.

Furthermore, GR in Eq. (1) can be expressed by the following equation according to the conventional procedure for growth analysis (Hidaka et al., 2015; Radford, 1967):

$$
G R=G R / L A I L A I / W W,
$$

where: $G R / L A I\left(\mathrm{gDW} \mathrm{m}^{-2} \mathrm{~d}^{-1}\right)$ is the net assimilation rate, corresponding to the leaf photosynthetic rate, $L A I\left(\mathrm{~m}^{2} \mathrm{~m}^{-2}\right)$ is the leaf area index (total leaf area per ground area), $W\left(\mathrm{gDW} \mathrm{m}{ }^{-2}\right)$ is the shoot dry weight of the crop canopy, ie $L A I / W\left(\mathrm{~m}^{2} \mathrm{~g}^{-1} \mathrm{DW}\right)$ gives the specific leaf area.

On the other hand, $Q_{\mathrm{N}} / G R$ in Eq. (1) can be divided into two terms by incorporating the evapotranspiration rate (ET, $\left.1 \mathrm{~m}^{-2} \mathrm{~d}^{-1}\right)$ as an indicator of water use per unit ground area:

$$
Q_{\mathrm{N}} / G R=Q_{\mathrm{N}} / E T E T / G R,
$$

where: $Q_{\mathrm{N}} / E T\left(\mathrm{gN} \mathrm{l}^{-1}\right)$ is the water use efficiency for $\mathrm{N}$ uptake for a catch crop technique, and $E T / G R\left(1 \mathrm{~g}^{-1} \mathrm{DW}\right)$ is the water requirement for dry matter production of a catch crop canopy (the reciprocal of the water use efficiency for growth) (Kramer and Boyer, 1995). If it is necessary to focus on the crop itself, $Q_{N} / E T$ in Eq. (3) can also be expressed by the following equation using the transpiration rate $\left(\operatorname{Tr}, 1 \mathrm{~m}^{-2} \mathrm{~d}^{-1}\right)$ :

$$
Q_{\mathrm{N}} / E T=Q_{\mathrm{N}} / \operatorname{Tr} \operatorname{Tr} / E T,
$$

where: $Q_{\mathrm{N}} / \operatorname{Tr}\left(\mathrm{gN}^{-1}\right)$ is the water use efficiency for $\mathrm{N}$ uptake based on the catch crop canopy, and $\operatorname{Tr} / E T\left(1^{-1}\right)$ is the ratio of transpiration to evapotranspiration, which is an important parameter for crop water management (Adekaku, 2006; Yasutake et al., 2011).

Based on Eqs (1)-(3), $Q_{\mathrm{N}}$ can be expressed by the equation below, which should facilitate the comprehensive understanding of $Q_{\mathrm{N}}$ in relation to growth and water use of the crop canopy.

$$
Q_{\mathrm{N}}=(G R / L A I L A I / W W)\left(Q_{\mathrm{N}} / E T E T / G R\right),
$$

Two cultivation experiments were conducted in 2011 and 2012 (from 22 April to 10 June for the 2011 experiment, and 29 September to 17 November for the 2012 experiment). Dent corn (Zea mays L. cv. 'KD731') as a catch crop was cultivated during a fallow period following commercial crop (water melon) cultivation in a naturally ventilated green-house $(7.7 \times 27 \mathrm{~m}$, roof and side windows $)$ at the Faculty of Agriculture, Kochi University $\left(33^{\circ} 33.3^{\prime} \mathrm{N}\right.$, $133^{\circ} 40.4^{\prime} \mathrm{E}$ ), Japan (Yasutake et al., 2011; 2014b). The greenhouse soil was sandy clay loam (clay, 14\%; silt, $21 \%$; sand, $65 \%$ ), and the physical properties of the topsoil layer were as follows: dry density of $1.40 \pm 0.06 \mathrm{~g} \mathrm{~cm}^{-3}$, particle density of $2.60 \pm 0.06 \mathrm{~g} \mathrm{~cm}^{-3}$, and porosity of $0.46 \pm$ $0.03 \mathrm{~cm}^{3} \mathrm{~cm}^{-3}$. Corn was cultivated for 7 weeks at three plant densities in field plots $(8 \times 1 \mathrm{~m}$ ); specifically, 7.3 (low treatment), 59.7 (normal treatment), and 119.5 (high treatment) plants $\mathrm{m}^{-2}$. Three plots were used for each density treatment and were randomly positioned in the greenhouse (three replicates for each treatment). A detailed description of the experimental design can be found in Yasutake et al. (2011). During the growing period, the natural ventilation system was automatically managed according to the inside 
air temperature, and a drip irrigation system was used to apply $2-5 \mathrm{~mm}$ of water to the plots daily to maintain a soil matric potential of approximately $-19.6 \mathrm{kPa}$.

Environmental elements (net radiation, solar radiation, air temperature, air relative humidity, wind speed, ground heat flux) were measured at a representative point in the greenhouse and automatically recorded on a data logger (NR-600, Keyence, Japan).

Three crop shoots were collected from each plot each week, and their plant height, leaf area, and dry weight were measured. The $L A I$ and $W$ in Eq. (2) were calculated from the leaf area and shoot dry weight of a single plant, multiplied by the plant density. The total $\mathrm{N}$ content in the dried shoot canopy was obtained from $W$ and the $\mathrm{N}$ concentration of the shoot dry matter, which was measured by a carbon and nitrogen analyzer (JM1000CN, J-SCIENCE GROUP, Japan). Next, the rate of $\mathrm{N}$ uptake by the catch crop canopy on a weekly basis $\left(Q_{N}\right)$ was evaluated from the weekly change in the $\mathrm{N}$ content of the shoot of crop canopy. On the other hand, $G R$ was evaluated as the increase in $W$ over the measurement interval (1 week).

The daily transpiration rate $(T r)$ and evaporation rate $(E)$ in one plot of each treatment were estimated using the Penman-Monteith model incorporating measured environmental elements including net radiation, air temperature and humidity, wind speed, ground heat flux, and specific parameters for the corn canopy in the greenhouse (Tahiri et al., 2006). The evapotranspiration rate $(E T)$ was obtained as the sum of $\operatorname{Tr}$ and $E$.

Detailed information about the measurements and analyses mentioned above can be found in Yasutake et al. (2011, 2014b). The data obtained in the 2012 experiments were applied to the comprehensive analysis procedure (Eqs (1)-(5)) on a weekly basis.

Furthermore, to analyze the effect of plant density on photosynthetic activity, the photosynthetic photon flux density $(P P F D)$, stomatal conductance $\left(G_{\mathrm{S}}\right)$, and quantum yield efficiency in photosystem II $\left(\Phi_{\mathrm{II}}\right)$ were measured in upper (7th) and lower (4th) leaves of the corn canopy (plant height: $0.85-0.93 \mathrm{~m})$ in the High $\left(L A I: 7.9 \mathrm{~m}^{2} \mathrm{~m}^{-2}\right)$, normal (LAI: $\left.4.7 \mathrm{~m}^{2} \mathrm{~m}^{-2}\right)$, and low $\left(L A I: 0.8 \mathrm{~m}^{2} \mathrm{~m}^{-2}\right)$ treatments around noon (1115-1215 h) on 20 May in the 2011 experiment. $P P F D, G_{\mathrm{S}}$, and $\Phi_{\mathrm{II}}$ were measured using a quantum photometer (LI-250, LI-COR Inc., USA), a leaf porometer (SC-1, Decagon Devices Inc., USA), and a portable chlorophyll fluorometer (MINI-PAM, Heinz Walz, Germany), respectively. The electron transport rate $(E T R)$, which is closely correlated with the photosynthetic rate, was calculated according to Jones (2014) as follows:

$$
E T R=\Phi_{\mathrm{II}} \text { PPFD } a \mathrm{~b},
$$

where: the coefficient $a$ is the fraction of absorbed quanta used by photosystem II and the coefficient $b$ is the light absorbance ratio in a leaf. The coefficients $a$ and $b$ were assumed to be 0.5 and 0.84 , respectively (Jones, 2014).
Statistical differences in $Q_{\mathrm{N}}$ and its component parameters $\left(G R, Q_{\mathrm{N}} / G R, G R / L A I, L A I / W, W, Q_{\mathrm{N}} / E T\right.$, and $\left.E T / G R\right)$, and PPFD, $G_{\mathrm{S}}, \Phi_{\mathrm{II}}$, and ETR among the three treatments were analyzed using the Tukey-Kramer test at $\mathrm{p}<0.05$. Linear regression analysis was conducted between $G R$ and $Q_{\mathrm{N}} / G R$, and between $Q_{\mathrm{N}}$ and its component parameters at $\mathrm{p}<0.05,0.01$, and 0.001 . These statistical analyses were performed using the statistical program $\mathrm{R}$ (version 3.0.2).

\section{RESULTS AND DISCUSSION}

In the 2012 experiment, from which data were applied to the comprehensive analysis of $\mathrm{N}$ uptake, mean values of daily cumulative solar radiation, air temperature, and relative humidity were $9.5 \mathrm{MJ} \mathrm{m}^{-2} \mathrm{~d}^{-1}, 21.1^{\circ} \mathrm{C}$, and $73.1 \%$, respectively. The dynamics of the greenhouse environment, and the growth, water use, and $\mathrm{N}$ uptake of the crop canopy are described in detail in a previous report (Yasutake et al., 2014b). Figure $1 \mathrm{~A}$ shows $Q_{\mathrm{N}}$ and its component parameters $\left(G R\right.$ and $\left.Q_{\mathrm{N}} / G R\right)$ on a weekly basis, but because those weekly changes had fluctuations, averages during the growing period (2nd to 7th week; 6 October to 17 November 2012) are also shown in Fig. 1B for comparison among the three treatments. Focusing on the weekly changes (Fig. 1A), $Q_{\mathrm{N}}$ increased from the 2 nd to 4 th week and then was approximately constant. The $G R$ gradually increased and reached a maximum around the 5th to 6th week and then slightly decreased. The $Q_{\mathrm{N}} / G R$, corresponding to the $\mathrm{N}$ concentration of crop dry matter, decreased with time because of crop growth, as reported by Yasutake et al. (2014b) and Zhao (2014). In general, a similar time change was present between $Q_{\mathrm{N}}$ and $G R$ as observed by Ciampitti and Vyn (2011) and an opposite change between $Q_{\mathrm{N}}$ or $G R$ and $Q_{\mathrm{N}} / G R$. When comparing these parameters among the three treatments (Fig. 1B), the pattern of $Q_{\mathrm{N}}$ averages was generally similar to that of $G R$ at the first glance, but $Q_{\mathrm{N}}$ was similar in the High and Normal treatments; however, a significant difference in $G R$ was found between the High and Normal treatments. This result can be attributed to a trade-off relationship between the averages of $G R$ and $Q_{\mathrm{N}} / G R$ (Fig. 1B), where there was a significant negative linear relationship between them $\left(G R=-11650 Q_{\mathrm{N}} /\right.$ $G R+518.7$, a correlation coefficient $r=-0.706, \mathrm{p}<0.05$ ) as shown in Fig. 2. These results are generally consistent with the reports of Ciampitti and Vyn (2011) and Yan et al. (2014), both of which also considered dynamic characteristics of growth, $\mathrm{N}$ concentration, and $\mathrm{N}$ uptake of corn crop.

The $G R$ as a component of $Q_{\mathrm{N}}$ was divided into $G R /$ $L A I, L A I / W$, and $W$ according to Eq. (2) and their values are shown on a weekly basis and as averages in Figs $3 \mathrm{~A}$ and $3 \mathrm{~B}$, respectively. Weekly $G R / L A I$, corresponding to the leaf photosynthetic rate, decreased over time (Fig. 3A), which is a frequently observed phenomenon (Yamauchi et al., 1988). In our study, this decrease is likely to be caused by leaves shading each other within the crop canopy and 


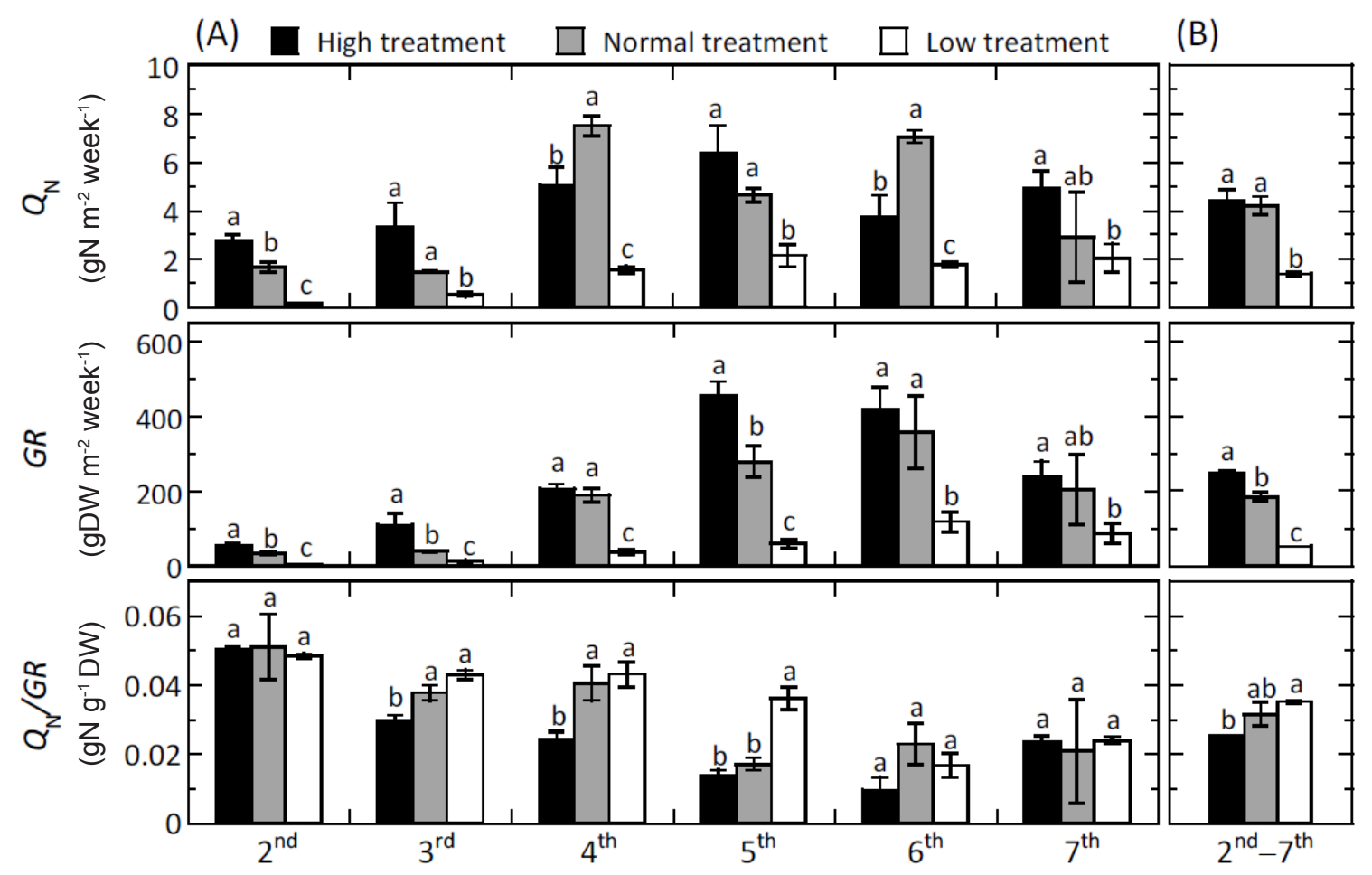

Weeks after sowing (week)

Fig. 1. Weekly changes in the nitrogen uptake rate $\left(Q_{\mathrm{N}}\right)$, growth rate $(G R)$, and nitrogen uptake rate per growth rate $\left(Q_{\mathrm{N}} / G R\right)(\mathrm{N}$ concentration of dry matter) of the corn canopy under different plant density treatments (high -119.5 , normal -59.7 , and low -7.3 plants $\mathrm{m}^{-2}$ ) from the 2 nd to 7 th week (6 October to 17 November, 2012) after sowing (A), and their averages over the growing period (B). The means and standard error bars are shown for each treatment $(n=3)$. Different letters represent significant differences at $\mathrm{p}<0.05$ from the Tukey-Kramer test. The weekly $Q_{\mathrm{N}}$ data was published in Yasutake et al. (2014b).

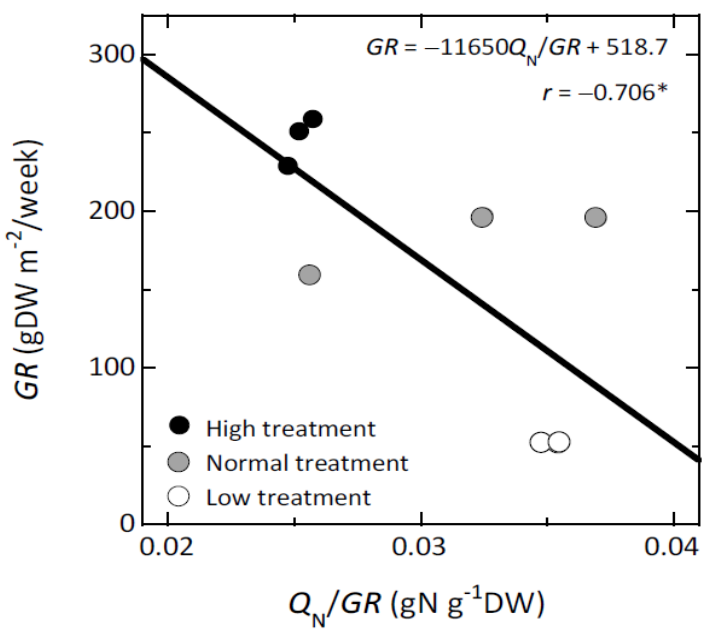

Fig. 2. Relationship between growth rate $(G R)$ and nitrogen uptake rate per growth rate $\left(Q_{\mathrm{N}} / G R\right)$ (N concentration of dry matter) of the corn canopy under different plant density treatments (high -119.5 , normal -59.7 , and low -7.3 plants $\mathrm{m}^{-2}$ ). Data of $G R$ and $Q_{\mathrm{N}} / G R$ were average values from the 2 nd to 7 th week (6 October to 17 November, 2012) after sowing. The linear regression line, and its equation and correlation coefficient $(r)$ are also shown. *represents significance of $r$ at $\mathrm{p}<0.05$. insufficient nutrients in the soil. A linear decrease over time was found for weekly $L A I / W$, while there was an exponential increase for weekly $W$. As a result, weekly $L A I$ (data not shown) increased alongside $W$. When we compared these values among the three treatments (Fig. 3B), GR/LAI was found to be significantly lower in the High treatment and higher in the Low treatment, while the opposite relationship was observed for $L A I$ (data not shown), caused by higher $L A I / W$ and higher $W$. The $L A I$ values at the harvest (7th) week were 21.6 and $14.2 \mathrm{~m}^{2} \mathrm{~m}^{-2}$ in the High and Normal treatments, respectively. These values are substantially higher than those of various other crops or usual corn cultivation (Ibrahim et al., 2016; Nakano et al., 2015). These high $L A I$ values are a characteristic feature of catch crop cultivation under high plant density (Yasutake et al., 2011, 2014a, 2014b). These results suggest that increasing plant density induces a lower photosynthetic rate per leaf area but larger leaves are produced through changing crop morphology (ie higher $L A I$ development as a result of higher $L A I / W$ and $W$ ).

To examine the photosynthetic activity of leaves in the three treatments, some environmental and physiological parameters were measured and/or evaluated at upper (7th) and lower (4th) leaves within the canopy (Fig. 4). For upper 


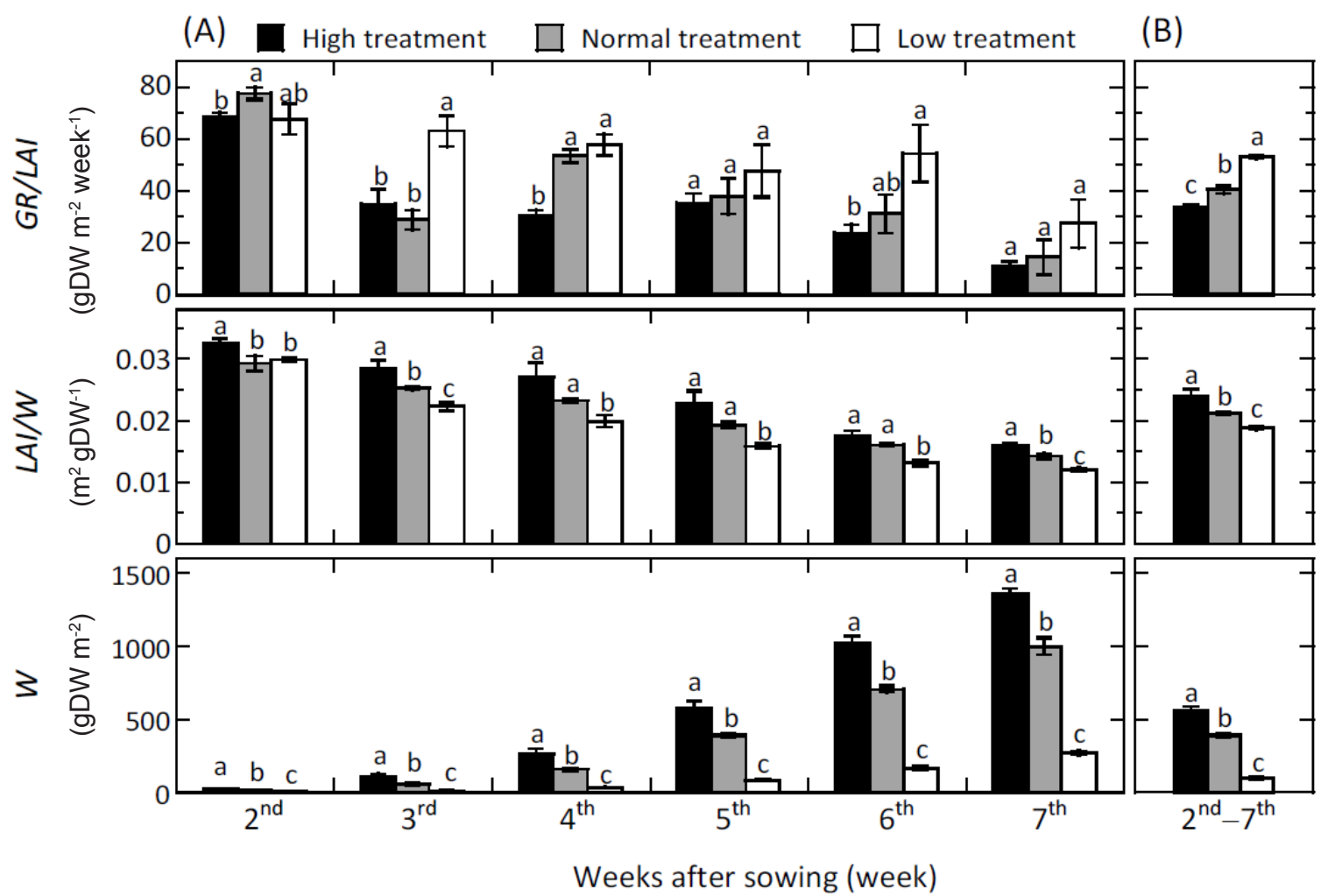

Fig. 3. Weekly changes in the growth rate per leaf area index $(G R / L A I)$ (= net assimilation rate), specific leaf area $(L A I / W)$, and shoot dry weight $(W)$ of the corn canopy in different plant density treatments (high -119.5 , normal -59.7 , and low -7.3 plants $\left.\mathrm{m}^{-2}\right)$ from the 2nd to 7th week (6 October to 17 November, 2012) after sowing (A), and their averages over the growing period (B). The means and standard error bars are shown for each treatment $(n=3)$. Different letters represent significant differences at $\mathrm{p}<0.05$ from the Tukey-Kramer test.

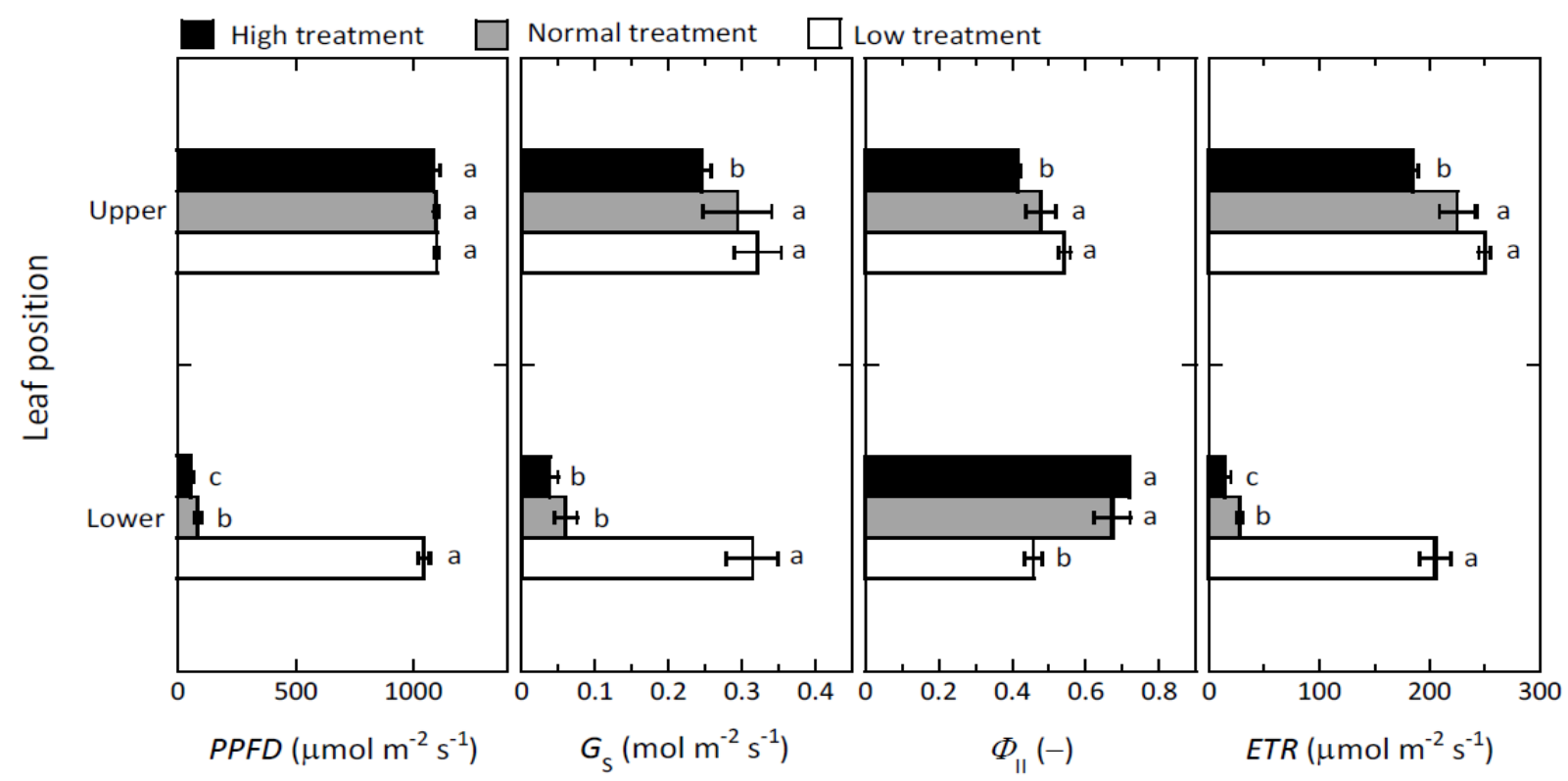

Fig. 4. Photosynthetic photon flux density $(P P F D)$, stomatal conductance $\left(G_{\mathrm{S}}\right)$, quantum yield efficiency in photosystem II $\left(\Phi_{\mathrm{II}}\right)$, and electron transport rate $(E T R)$ of leaves in upper (7th) and lower (4th) positions in the corn canopy in different plant density treatments (high -119.5 , normal - 59.7, and low - 7.3 plants $\mathrm{m}^{-2}$ ) around noon on clear day (at 1115-1215 h on 20 May, 2011). The means and standard error bars are shown for each treatment $(n=3)$. Different letters represent significant differences at $\mathrm{p}<0.05$ from the TukeyKramer test. 


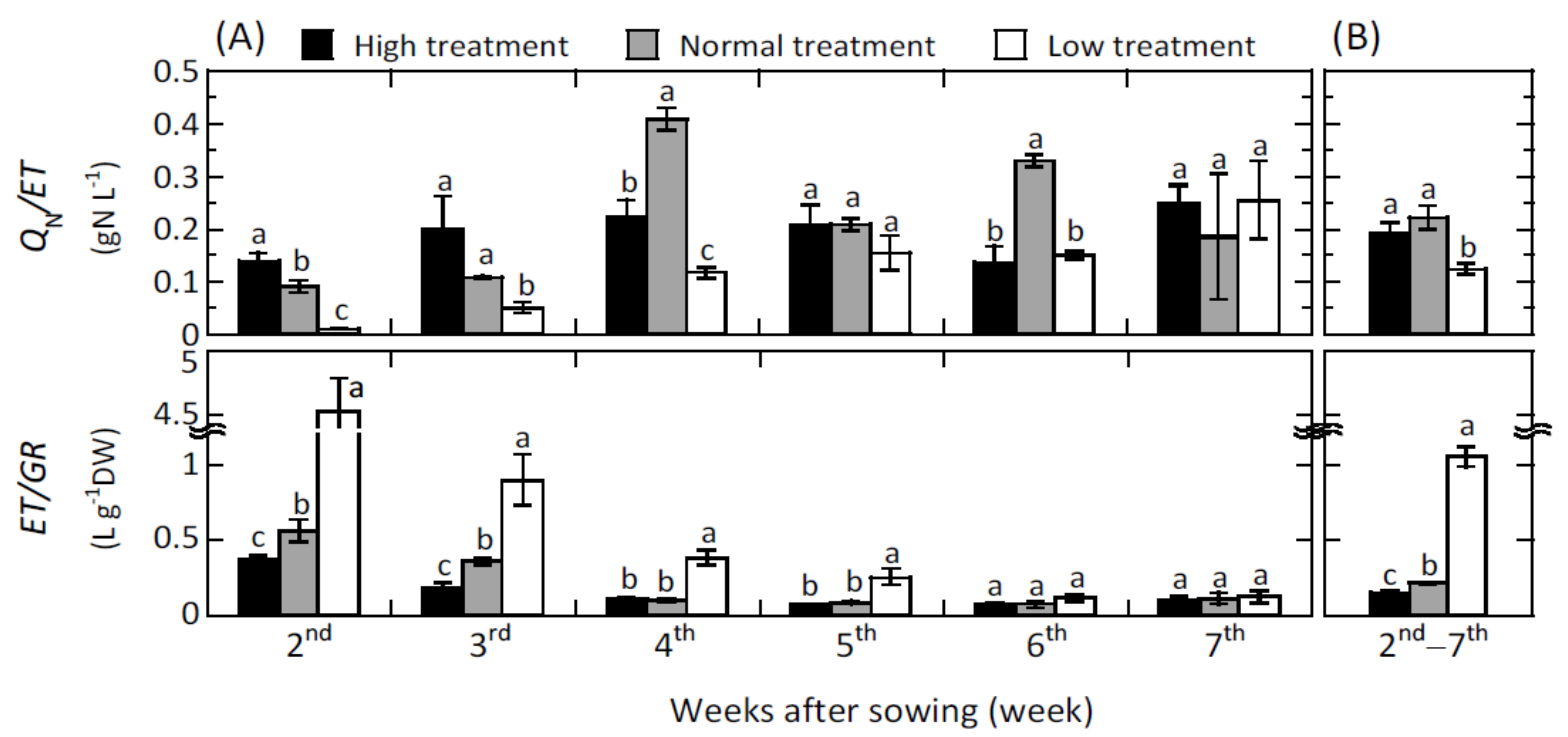

Fig. 5. Weekly changes in the nitrogen uptake rate per evapotranspiration rate $\left(Q_{\mathbb{N}} / E T\right)$ (= water use efficiency for $\mathrm{N}$ uptake) and evapotranspiration rate per growth rate $(E T / G R)$ (= water demand for growth) of the corn canopy in different plant density treatments (high - 119.5, normal - 59.7, and low -7.3 plants $\mathrm{m}^{-2}$ ) from the 2 nd to 7 th week (6 October to 17 November, 2012) after sowing (A), and their averages over the growing period (B). The means and standard error bars are shown for each treatment $(n=3)$. Different letters represent significant differences at $\mathrm{p}<0.05$ from the Tukey-Kramer test.

leaves, $P P F D$ was almost the same in all three treatments, but $G_{\mathrm{S}}$ was lower in the High treatment than the other treatments. In addition, ETR was lower because of the lower $\Phi_{\mathrm{II}}$. For lower leaves, $P P F D$ was extremely low in the High and Normal treatments because of their dense planting. As a result, $G_{\mathrm{S}}$ and ETR were also much lower in the High and Normal treatments. This suggests lower photosynthetic activity of leaves with higher plant density and is consistent with the $G R / L A I$ data (Fig. 3).

On the other hand, Nagare et al. (2010) and Yan et al. (2014) reported that more $\mathrm{N}$ is accumulated in leaves than in other parts of the shoots. Therefore, from the viewpoint of crop morphology, higher plant density is desirable for catch crop cultivation.

The $Q_{\mathrm{N}} / G R$ was further divided into $Q_{\mathrm{N}} / E T$ and $E T / G R$ by accounting for water use (ie evapotranspiration) according to Eq. (3); those results are shown in Fig. 5 in the same manner of Figs 1 and 3. Weekly $Q_{\mathrm{N}} / E T$, water use efficiency for $\mathrm{N}$ removal, increased from the 2 nd to 4 th or 5 th week, particularly in the Low treatment (Fig. 5A). Nutrient uptake by roots strongly depends on transpiration water streams (Kramer and Boyer, 1995; Nomiyama et al., 2015), and Yasutake et al. (2014b) observed a positive linear relationship between $Q_{\mathrm{N}}$ and $\operatorname{Tr}$ of a catch crop field. This suggests that $\operatorname{Tr}$ in $E T$ is a key factor and $E$ can be regarded as water loss for $\mathrm{N}$ removal. The weekly change in ratio of $T r$ to ET $(\operatorname{Tr} / E T)$ for the three treatments increased with time because of crop growth (ie ground cover development with vegetation) and its value was lower in the Low treatment than in the High treatment (data not shown). This should explain the $Q_{\mathrm{N}} / E T$ behaviour shown in Fig. 5. Furthermore, weekly $E T / G R$ (the reciprocal of the water use efficiency for growth) decreased over time and after the 6th week, there was no difference among the three treatments, all of which had fairly low values for $E T / G R$. This can also be attributed to the ground cover development with crop growth (Nyakudya and Stroosnijder, 2014), which should decrease $E$ as water loss for crop growth.

As a result, the average $Q_{\mathrm{N}} / E T$ and $E T / G R$ for the high and normal treatments were significantly higher (1.57-1.80 fold) and lower (0.14-0.20 fold), respectively, than those of the Low treatment (Fig. 5B). The average value of $E T / G R$ in the Low treatment (Fig. 5B) was within a range observed by Benjamin et al. (2015) of about $0.5-1.25 \mathrm{l} \mathrm{g}^{-1} \mathrm{DW}$. This indicates that higher plant density plots (High and Normal treatments) have higher water use efficiencies for $\mathrm{N}$ removal and crop growth.

Figure 6 shows the hierarchical structure of $Q_{\mathrm{N}}$ with its component parameters and $r$ values for linear relationships between $Q_{\mathrm{N}}$ and its parameters. For $G R$ and $Q_{\mathrm{N}} / E T$ derived from $Q_{\mathrm{N}}$ by Eq. (1), GR had a significant linear relationship with $Q_{\mathrm{N}}$ but not $Q_{\mathrm{N}} / E T$. However, Eq. (3) enabled us to significantly relate $Q_{\mathrm{N}}$ to $Q_{\mathrm{N}} / E T$ and $E T / G R$. As a result, Eq. (5) successfully divided $Q_{\mathrm{N}}$ into five effective parameters $\left(G R / L A I, L A I / W, W, Q_{\mathrm{N}} / E T\right.$, and $\left.E T / G R\right)$ based on agrophysics and physiology. All of these parameters had simple and significant linear relationships with $Q_{\mathrm{N}}$; a positive correlation was found for $L A I / W, W$, and $Q_{\mathrm{N}} / E T$, and a negative correlation for $G R / L A I$ and $E T / G R$. Such linear relationships improve our understanding of the composition of $Q_{\mathrm{N}}$ as an agrophysical and physiological factors in cropping systems. 


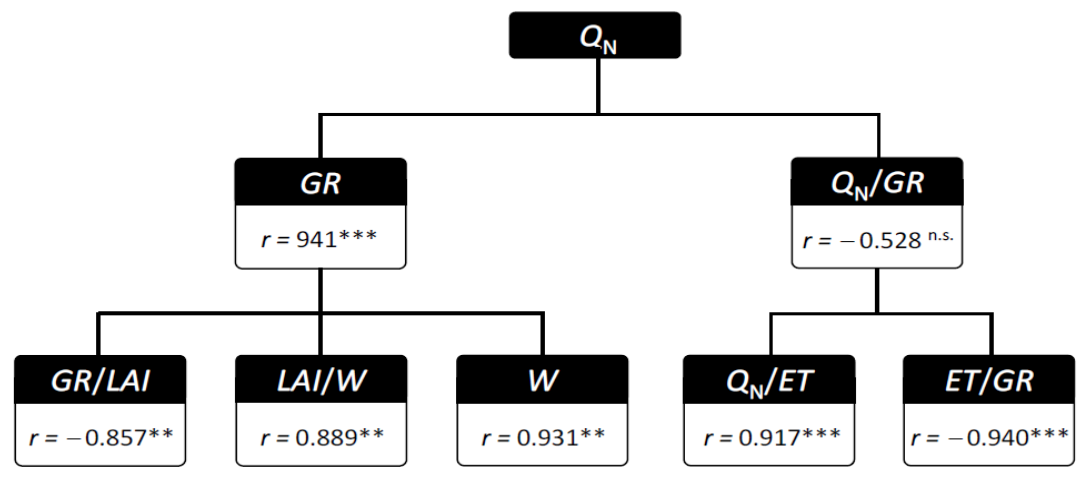

Fig. 6. Schematic diagram of the relationship between the nitrogen uptake rate $\left(Q_{\mathrm{N}}\right)$ and its component parameters, and their correlation coefficients ( $r$ ). See Eqs (1)-(3), and (5) for definitions of the respective symbols. ** and *** represent significance of $r$ at $\mathrm{p}<0.01$, and 0.001 , respectively, and n.s. represents non-significance of $r$.

\section{CONCLUSIONS}

1. New methodology was proposed for the comprehensive analysis of $\mathrm{N}$ removal by a catch crop canopy which performance has been demonstrated but its mechanism has not been fully understood in past studies. The $\mathrm{N}$ removal performance can be divided into five effective parameters in relation to crop growth and water use efficiency.

2. This analytical methodology was then applied to the data from a cultivation experiment (Yasutake et al., 2014b). The mechanisms behind the effect of plant density on $\mathrm{N}$ removal were analyzed comprehensively, in which increasing plant density resulted in higher crop growth driven by the production of larger leaves with high $\mathrm{N}$ accumulation and lower water loss by evaporation from the soil surface. As a result, we found that higher plant densities are advantageous for not only total $\mathrm{N}$ removal but also water use efficiency for crop growth and $\mathrm{N}$ removal.

3. The five parameters all had significant linear relationships with $\mathrm{N}$ removal; a positive correlation was found for three parameters (specific leaf area, shoot dry weight, and water use efficiency for $\mathrm{N}$ removal) and a negative correlation for the others (net assimilation rate and water requirement for growth).

4. The new methodology made it possible to express the $\mathrm{N}$ removal in terms of the agrophysical/physiological and statistical significant parameters, and therefore enhance our understanding of the components of the $\mathrm{N}$ removal mechanisms and their interactions. These results indicate the effectiveness of the new comprehensive analytical methodology, which will contribute to designing an adequate plant density based on the field situations (eg available water amount and soil $\mathrm{N}$ quantity to be removed) in catch crop cultivation for effective and sustainable greenhouses management.

Conflict of interest: We declare that there are no contractual relations, financial associations or other relationships that could influence the content of the article.

\section{REFERENCES}

Adekaku K.O., 2007. Simulating the effects of irrigation scheduling on cowpea yield. Int. Agrophysics, 20, 261-267.

Benjamin J.G., Nielsen D.C., Vigil M.F., Mikha M.M., and Calderon F., 2015. Cumulative deficit irrigation effects on corn biomass and grain yield under two tillage systems. Agric. Water Manag., 159, 107-114.

Bonachela S., Granados M.R., López J.C., Hernández J., Magá J.J., Baeza E.J, and Baille A., 2012. How plastic mulches affect the thermal and radiative microclimate in an unheated low-cost greenhouse. Agric. For. Meteorol., 152, $65-72$.

Ciampitti I.A. and Vyn T.J., 2011. A comprehensive study of plant density consequences on nitrogen uptake dynamics of maize plants from vegetative tot reproductive stages. Field Crops Res., 121, 2-18.

Fujimaki H. and Kikuchi N., 2010. Drought and salinity tolerances of young Jatropha. Int. Agrophys., 24, 121-127.

Fujiwara T., 2012. Concept of an innovative water management system with decentralized water reclamation and cascading material-cycle for agricultural areas. Water Sci. Technol., $66,1171-1177$.

Fujiwara T., Ohtoshi K., Tang X., and Yamabe K., 2002. Sequential variation of groundwater quality in an agricultural area with greenhouses near the coast. Water Sci. Technol., 45, 53-61.

Hidaka K., Dan K., Imamura H., Takayama T., Sameshima K., and Okimura M., 2015. Variety comparison of effect of supplemental lighting with LED on growth and yield in forcing culture of strawberry. Environ. Control Biol., 53, 135-143.

Ibrahim M.M., El-Baroudy A.A., and Taha A.M., 2016. Irrigation and fertigation scheduling under drip irrigation for maize crop in sandy soil. Int. Agrophys., 30, 47-55.

Jones H.G., 2014. Plants and Microclimate. A Quantitative Approach to Environmental Plant Physiology. Ed. Cambridge University Press, New York, USA.

Kondo K., Inoue K., Fujiwara T., Yamane S., Yasutake D., Maeda M., Nagare H., Akao S., and Ohtoshi K., 2013. Seasonal changes in the performance of a catch crop for mitigating diffuse agricultural pollution. Water Sci. Technol., 68, 776-782. 
Kramer P.J. and Boyer J.S., 1995. Water Relations of Plants and Soils. Academic Press, San Diego, USA.

Min J., Shi W., Xing G., Zhang H., and Zhu Z., 2011. Effect of a catch crop and reduced nitrogen fertilization on nitrogen leaching in greenhouse vegetable production systems. Nutr. Cycl. Agroecosyst., 91, 31-39.

Nagare H., Inoue T., Fujiwara T., Akao S., Maeda M., and Yamane S., 2010. Phosphorus extraction from corn for recovery and recycle (in Japanese). Environ. Eng. Res., 47, 459-464.

Nakano S., Tacarindua C.R.P., Nakashima K., Homma K., and Shiraiwa T., 2015. Evaluation of the effects of increasing temperature on the transpiration rate and canopy conductance of soybean by using the sap flow method. J. Agric. Meteorol., 71, 98-105.

Nomiyama R., Yasutake D., Sago Y., Mori M., Tagawa K., Cho H., Wu W., Wang W., and Kitano M., 2015. Evapotranspiration integrated model for analysis of soil salinization affected by root selective absorption. Environ. Control Biol., 53, 199-204.

Nyakudya I.W. and Stroosnijder L., 2014. Effect of rooting depth, plant density and planting date on maize (Zea mays L.) yield and water use efficiency in semi-arid Zimbabwe: Modelling with AquaCrop. Agric. Water Manag., 146, 280-296.

Radford P.J., 1967. Growth analysis formulae - Their use and abuse. Crop Sci., 7, 171-175.

Redwan M., Spinelli F., and Mancuso S., 2016. Role of ion transporters in salinity resistance in plants. Environ. Control Biol., 54, 1-6.

Rinnofner T., Friedel J.K., De Krujff R., Pietsch G., and Freyer B., 2008. Effect of catch crops on $\mathrm{N}$ dynamics and following crops in organic farming. Agron. Sustain. Dev., 28, 551-558.

Sadamatsu A., Fujiwara T., Ohtoshi K., and Maeda M., 2008. Effect of flooding activities in a greenhouse on the production and emission of nitrous oxide (in Japanese). Environ. Eng. Res., 45, 459-466.
Shi W., Yao J., and Yan F., 2009. Vegetable cultivation under greenhouse conditions leads to rapid accumulation of nutrients, acidification and salinity of soils and groundwater contamination in South-Eastern China. Nutr. Cycl. Agroecosyst., 83, 73-84.

Tahiri A.Z., Anyoji H., and Yasuda H., 2006. Fixed and variable light extinction coefficients for estimating plant transpiration and soil evaporation under irrigated maize. Agric. Water Manage., 84, 186-192.

Yamauchi A., Kono Y., and Tatsumi J., 1988. Comparative growth analysis of upland rice and maize grown under different soil moisture conditions. Jpn. J. Crop Sci., 57, 174-183

Yan P., Yue S., Qui M., Chen X., Cui Z., and Chen F., 2014. Using maize hybrids and in-season nitrogen management to improve grain yield and grain nitrogen concentration. Field Crops Res., 166, 38-45.

Yasutake D., Awata K., Kondo K., Yamane S., Matsuoka M., Maeda M., Nagare H., Nomiyama R., Sago Y., Kitano M., and Fujiwara T., 2014a. Advantages of pre-harvest temporal flooding in a catch crop field in relation to soil moisture and nutrient salt removal by root uptake. Biologia, 69, 1577-1584.

Yasutake D., Kiyokawa C., Kondo K., Nomiyama R., Kitano M., Mori M., Yamane S., Maeda M., Nagare H., and Fujiwara T., 2014b. Characteristics of nutrient salt uptake associated with water use of corn as a catch crop at different plant densities in a greenhouse. Pedosphere, 24, 339-348.

Yasutake D., Kimura C., Kondo K., Inoue K., Mori M., Yamane S., Maeda M., Nagare H., and Fujiwara T., 2011. Analyzing evapotranspiration components and crop coefficients for catch crop field with small area at different plant densities in a greenhouse. Environ. Control Biol., 49, 217-225.

Zhao B., 2014. Determining of a critical dilution curve for plant nitrogen concentration in winter barley. Field Crops Res, 160, 64-72. 